\title{
A Cutting-Edge Approach to Risk Management Framework: Upswing Customs Administration
}

\author{
Agung Endika Satyadini \\ Pandawa Institute, Indonesia (www.pandawa-institute.com) \\ E-mail: agung.satyadini@gmail.com \\ Abdul Basir \\ Jayabaya University, Indonesia \\ E-mail: abdulbasir8571@gmail.com \\ Adi Barata \\ Jayabaya University, Indonesia \\ E-mail: adibarata@gmail.com
}

Received: Sep. 8, 2019 Accepted: Dec. 9, $2019 \quad$ Published: January 1, 2020

doi:10.5296/jmr.v12i1.16011

URL: https://doi.org/10.5296/jmr.v12i1.16011

\begin{abstract}
It is worth observing that in the context of customs administration, risk management plays a crucial role in coordinating activities to direct and control risk that help customs officials for addressing the problem of limited resources, increased trade volume, and the need for prompt clearance. However, it is also worth highlighting that customs risk management framework needs to be dynamically improved to meet the changes in global value chain. This study analyzed the successful experiences in area of risk management, as well as important international documents, recommended by World Customs Organization and proposed a cutting-edge approach of customs risk management framework including artificial intelligence, in accordance with the importance of risk management in the process of trade facilitation and customs procedures.
\end{abstract}

Keywords: Risk Management, Customs, Artificial Intelligence 


\section{Introduction}

While sound modern risk management is the cornerstone of achieving a good trade facilitation and control, it is nevertheless often a costly response to any given inefficiency in international trade and international mobility of goods. Consequently, consideration of the external legislative context represents an attempt to look at existing legislation in action to identify weaknesses and threats that may need to be addressed or mitigated through administrative practices.

A body of literature has grown up in this brain area of traditional risk management in supporting the institutional reform based on the use of risk-based thinking in accordance with the requirements of international standards. Renewed interests also lifted regarding the need of modern risk management to be simultaneously adopted in formulating the modern risk management. Further, in the context emerging countries in Southeast Asia, of it is also worth acknowledging that border activities have significantly increased from 2010 to 2014, the annual average growth rate is equal to $9.55 \%$ per year in Association of Southeast Asian Nations (ASEAN) members (WCO, 2015).

It is worth noting that WCO is an inter-government organization that has 180 members throughout the world, and it has responsibility for providing international standards and guidelines (WCO, 2009). WCO contributed to many customs administrations for improvement and implementation by adopting risk management (WCO, 2008). Recently, risk management is considered as one of the guiding principles of modernization of customs administration (WCO, 2011). However, it is essential to be understand that these international standards and guidelines may not be applied in all countries as it is because of specific circumstances. ${ }^{1}$

In the context of supply chain security and trade facilitation, several global concepts emerged as the global Customs community's concerted response to threats to the supply chain security, equally supporting facilitation of legitimate and secure businesses. These global concepts should prescribe baseline standards that have been tested and are working well around the globe. Further, the international instrument also should endeavor to usher a safer world trade regime and heralds a new approach to working methods and partnership for both customs and business towards a common goal based on trust.

This paper seeks to identify the fundamental factors of modern risk management implementation in supporting the institutional reform by adopting the modern risk management systems based on the use of risk-based thinking in accordance with the requirements of international standards. The paper organized as follows. Section 2 defines the literature review. Section 3 summarizes the acquired data and facts. Section 4 comprises the discussion and practical consideration, and Section 5 concludes.

\section{Literature Review}

Several literatures emphasized that trade facilitation and economic integration is accepting

\footnotetext{
${ }^{1}$ WCO (2012) emphasized that risk management should be adopted on the tailor-made strategy of each country because one size will not fit all customs administrations. In the similar vein, Mikuriya (2012) explained that the issued guidelines should be designed to correspond with the political, economic, and social circumstances of each administration's situation.
} 
phenomenal consideration and has turned into the fundamental part in WCO negotiations, inventory network security, capacity building and modernization programs, as the result business and government partners stand to pick up from trade facilitation's improvement, harmonization, institutionalization and modernization aims. ${ }^{2}$ In a broader context, WCO (2010) emphasized that border control agencies such as customs play a crucial role in supporting this flow. As a result, balancing customs control with the benefits of facilitating cross-border traffic in people and goods is very important. Hence, customs authorities must come up with strategies to allocate their resources to maximize their resources by introducing risk management. It will help customs administrations to achieve effective customs control and promote trade facilitation as well as protect society (WCO, 2008).

Turning now to the trade facilitation context, it is broadly accepted that trade facilitation can be seen in different terms - in restricted and more comprehensive terms, enhancing the goods flow through one's own customs gives off an impression of being enhancing the importation of products instead of the exportation of merchandise. However, even in this constrained point of view, trade facilitation can have critical ramifications for the simplicity and effectiveness of export. ${ }^{3}$

\section{Risk and Mitigation}

There is abundant literature in the brain area of risk and its mitigation. Da Silva Braga (2001) stated that risk is the possibility of events or activities that can prevent an organization from achieving its goals and Skipper (2007) also pointed out that risk can be anything that relates to the variability of results or consequences. Another expert defined risk as the lifeblood of every administration and it is important for administrations to focus on managing risk before it occurs (Shimpi, 2001). However, risk does not always refer to the negative impact or outcome because it can create some opportunities as well (Gupta, 2011). Generally, risk is seen as uncertainty associated with a future outcome or event (World Bank, 2004).

Several studies have documented the administrative and legislative framework of risk management. According to Widdowson (1998), the legislative framework of risk management must be based on flexible and tailored solutions to be implemented as well as the responsibilities will fall on both government and the trading community to achieve compliance in contrast with the traditional style of the management, which was based only on the trading community. Nonetheless, the administrative framework of risk management should be dependent and corresponds to the level of risk and the system should focus on post-transaction compliance assessments including effective appeal mechanisms especially on high- risk areas and vice versa (Sparrow, 2000).

Furthermore, Chapman \& Ward (1997) posited that the basic questions to be considered is the way to ask what was to be done, how, when, by whom and what was the cost. Accordingly,

\footnotetext{
2 According to the Asia-Pacific Trade and Investment Report, "the Asia-Pacific regions as a whole are now the largest trading region in the world with a $38 \%$ share of world exports, and $37 \%$ of world imports" (ESCAP, 2014).

3 The possibility of complementary bringing of hindrances down to exchange having expert fare impacts has considerably more significance when a wide range of strategy and different boundaries are considered. In such manner hindrances other than customs systems (e.g., transport framework and intensity of transport and different administrations) might be more vital for a few governments (Milner, Morrissey \& Evious Zgovu, 2008).
} 
Morris and Hough (1987) argued the importance of having clear objectives for implementing risk management systems in an organization. Thus, it must be handled as the best practice for organizations, which would focus on the interest of its organizations and their employees throughout well-developed policies, standards, procedures and plans (Blyth, 2009).

\section{Risk Management}

In the Revised Kyoto Convention, it also provides some common approaches of risk management which is defined as a customs control application as noted in Standard 6.3 Chapter 6 Customs Control (WCO, 2006). The methodology outlined in the Compendium establishes a common framework. However, its framework stays flexible to meet the unique conditions of each individual country. De Wulf (2004) pointed out that "risk management involved the systematic system of risk assessment, profiling, and selectivity, intelligence gathering, and analyses and also suggested that this system can help customs to target high risk in many activities such as cargos, traders as well as passengers, while maintaining effective and efficient controls at all stages of clearance".

In the past, risk management was considered as removing or reducing the possibility of failure or unexpected performance as well as creative thinking and capturing opportunities in terms of effective information flows and staff cooperation (Chapman and Ward, 1997). Additionally, Turner (1992) stated, "a risk-based management project was considered as an endeavor in which human, material, financial resources and legislative framework were managed to cope with constraints on cost and time in order to achieve the completion of certain objectives." The main point of this statement is to emphasize the need for an organization to gather a variety of available resources to reach its objectives.

It has been demonstrated that the idea of risk in any organization alludes to the likelihood of occasions and events happening that may keep an association from accomplishing its targets. Customs all over the world are required to accomplish two essential goals-work on smooth goods delivery between the countries and guarantee consistence with customs procedures. To some extent any organization uses a risk management system, even if it is not the formal one. Trying to meet its targets, customs should apply procedures to identify illegal action with an end goal to decrease its dangers (Widdowson, 2005).

A more conservative approach included a customs inspection of virtually all goods and passengers, which did not mean the high efficiency of this approach. However, with the development of scientific progress and expansion of globalization, paying special role of trade facilitation, customs revised its approaches on control. As an outcome, numerous organizations have actualized a more trained and organized way to deal with overseeing hazard, which also has helped them to build the productivity of their operations and to streamline their procedures and systems.

Minimizing the intervention in trade transaction and to reduce regulatory burden, a well-defined and structured risk management system must be implemented. Further, making full use of risk assessment methods, one needs to know who is moving what, to whom, from where. Data on the real parties behind the transaction and the movement of goods (buyer and 
seller or owner), and on the precise goods involved, is essential as is information on the routing of the goods throughout the supply chain (COM, 2012). For instance, the introduction of an Authorized Economic Operator (AEO) program is one senior policy decision and treatment by a top-level risk owner to reduce trade supply chain security risks. ${ }^{4}$

The basic international standards that define the principles and main directions of activity of the customs authorities in the field of risk management are the standard rules of Chapter 6 "Customs control" and other chapters of the International Convention on the Simplification and Harmonization of Customs Procedures Kyoto Convention. The main recommendations in the field of risk management are presented in Figure 1.

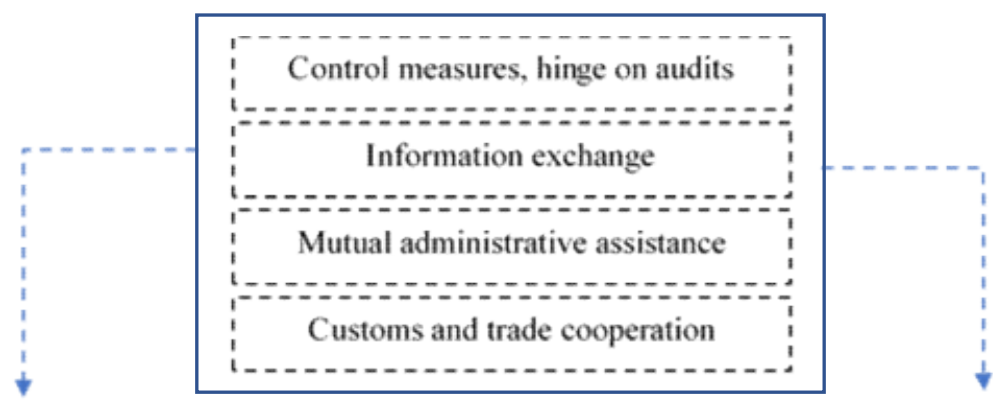

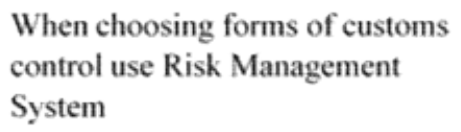

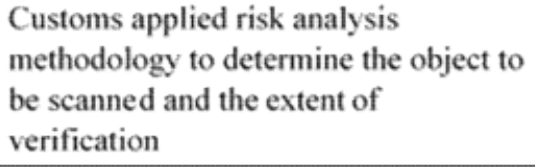

Source: Revised Kyoto Convention

Figure 1. Risk Management Recommendation

\section{Benefit of Customs Risk Management}

Gates (2006) argued that implementation of risk management programs resulted in the following benefits: greater enterprise-level risk information, more precise risk terminology, quantifying risks to the greatest extent possible, reduced risk of non-compliance, and increased awareness and accountability among staff. Kleffner (2003) suggested that academics assert that holistic corporate-wide risk management results in a reduced total risk level and establish a virtuous culture of vigilant risk monitoring in an organization. Kucuk (2006) concluded that successful risk management programs help business operations run more smoothly and effectively in a turbulent business environment. The results also indicate strong assurance among customs that risk management is the key methodology to simultaneously improve customs control and security on the one hand and trade facilitation on the other. In addition, the respondents expressed a general consensus that by using risk management, customs can improve overall management processes, which eventually leads to improved risk-based resource allocation. The benefits relating to reputation are ranked between medium and high in relevance. In addition, a partnership-oriented relationship with

\footnotetext{
${ }^{4}$ The status afforded to AEOs provides assessment information to the mid-level risk owner who may oversee the use of intelligence-driven profiles, risk indicator assessment, training and experience to determine whether a non-intrusive inspection or even a physical inspection by the field level risk owner is required.
} 
the private sector and a good reputation for predictable and fast service delivery can have a significant impact on the competitiveness of the country and its attractiveness for foreign direct investments (Cross-border Research Association, 2011).

\section{SAFE Framework}

In the brain area of conceptual terminology in accordance with risk management system, WCO (2018) posited that SAFE Framework covers four fundamental elements including: (1) the regulation of advance electronic cargo information requirements on inbound, outbound and transit shipments; (2) addressing the security threats, it provides a consistent risk management approach among members; (3) in accordance with comparable risk targeting methodology, it enables the reasonable request of the receiving nation, and sending nation's customs administration will perform an outbound inspection of high-risk cargo and/or transport conveyances, preferably using non-intrusive detection equipment such as large-scale X-ray machines and radiation detectors; (4) the suggestion of minimal supply chain security standard in the context of customs requirement. Further, the SAFE Framework also considers the critical elements of capacity building and requisite legislative authority. While certain aspects of this instrument can be implemented without capacity building, it is recognized that many administrations will need assistance to implement the standards. In this context, SAFE Framework contemplates appropriate assistance with capacity building for those Customs administrations that adopt it.

A considerable amount of literature has been published on the importance of risk management framework in customs administration. In this context, it is worth noting that WCO (2018) also suggested that one of the main thrusts of the SAFE Framework is to establish and enhance Customs-to-Customs network arrangements to promote a seamless movement of goods through secure international trade supply chains, which result in the exchange of timely and accurate information that will place customs administrations in the position of managing risk on a more effective basis. In a broader context, however, not only will this improve the ability of Customs to detect high-risk consignments, it will also enable Customs administrations to improve their controls along the international trade supply chain and make for better and more efficient allocation of Customs resources. Practically, the Customs-to-Customs network arrangements will strengthen co-operation between Customs administrations and enable administrations to carry out controls earlier in the supply chain, e.g. where the administration of an importing country requests the administration of the exporting country to undertake an examination on its behalf.

The most interesting aspect of the customs modernization is the needs of customs administrations to cope with the challenges of the new international trading environment by putting the building blocks in place to undertake Customs reform and modernization. In this sense, SAFE Framework has also been structured in a flexible manner to enable Customs administrations to move at different speeds. ${ }^{5}$

5 This will enable Customs administrations to implement it in line with their own unique levels of development, conditions and requirements 


\section{Artificial Intelligence (AI) and Risk Management}

A growing body of literature suggested that AI is increasingly becoming popular and due to its involvement of advanced technology platforms that able to address complex situations that are characterized by ambiguity and uncertainty. López-Robles et al (2019) analyzed that AI regarded as a process for gathering, analyzing, interpreting and disseminating high-value data timed to use in decision-making process- constitutes a framework for action and research for organizations aspiring to improve their competitiveness using high-value data in their risk management Fan et al (2017) emphasized that Risk control and management solutions based on AI analytical techniques are considered as resources and capabilities that should be developed and maintained at the risk management framework level by sharing costs and benefits of such assets. Risk assessment, control, and management are based on data and information. This information should be shared among the supply chain (or, broadly speaking, commercial processes) participant, then analyzed to assess the risk of participants, and finally used for risk management decision. In the same vein, Žigiene, Rybakovas and Alzbutas (2019) suggested that cognitive analysis or artificial intelligence helps to integrate complex large-scale data to indicate and integrate known and initially unknown risk factors for large business data processing by identifying risk factors for commercial processes. Assumptions for the use of artificial intelligence are the increasing computer computation capacity and the retention of data storage. In decision situations where the stakes are very high, the following principles are of crucial importance: (1) expensive precautions can be worth the cost even for low-probability risks, provided there is enough to win/lose thereby (Peterson, 2009); and (2) when there is little consensus in an area amongst experts, epistemic modesty is advisable. That is, one should not have too much confidence in the accuracy of one's own opinion either way.

\section{Research Methodology}

In the light of discussion regarding the identification of fundamental factors of the SAFE Framework and modern risk management to be implemented in customs, to provide the appropriate concept on institutional reform by adopting the modern risk management system hinge on the use of risk-based analysis in accordance with the requirements of international standards, this paper employs three approaches including: (i) Qualitative Description, by analyzing the problem with the way to describe through the adoption of modern risk management and SAFE Framework; (ii) Descriptive Research, by demonstrating a research result in a merely specific conclusion; and (iii) Qualitative Research, by adopting post-positive philosophy, utilized to exercise the object's practical and natural circumstance.

\section{Discussion}

\section{Competitive Advantage of Risk Management Adoption in Customs Administration}

The key is to actively motivate the client population towards the low-risk category. This can be achieved by providing incentives for traders, passengers or stakeholders to comply, and by operating a credible enforcement regime, which effectively and efficiently detects and punishes for non-compliance. In other words, affecting client behavior and actively steering 
the population towards low risk will allow customs authorities to concentrate more on controlling resources on high risks. For instance, fewer shipments or passengers that require customs intervention, therefore the workforce can be more productive processing in greater volumes but less time. Risk management has many potential benefits. They include supporting strategic and business planning, promoting continuous improvement, fewer shocks and unwelcome surprises, a quick grasp of new opportunities, enhancing internal and external communication, reassuring stakeholders, and helping to focus organizational programs.

Any risk management methodology should be flexible, adaptable, and consider changes in the operating environment at both national and international level. From an organizational perspective, effective risk management policies will result in a sustained and transparent risk management environment. This environment would see all employees take responsibility for managing risk and make decisions based on sound risk assessment practices. In turn, this would lead to more effective and efficient resource deployment and enable a continuous monitoring and evaluation culture that leads to better operational results, and the ability to respond and recover quickly and effectively when risks are realized.

From a government and wider stakeholder perspective, further benefits of risk management include a better balance between Customs control and trade facilitation, enhanced focus on high risk movements of goods and passengers, improved compliance with laws and regulations, reduced release times, lower transaction costs, the creation of a more level playing field for business, improved cooperation between traders and Customs, and a better foundation for more efficient revenue collection (Background Paper on Risk Management, 2010).

As indicated earlier, The Global Risk Management Survey (2009) interviewed practitioners from multiple industry sectors around the globe. In the survey, a lower total cost of insurable risk was ranked as the number one benefit of coordinated and consistent risk management programs. ${ }^{6}$ According to a survey carried out by Gates (2006), implementation of risk management programs resulted in the following benefits: greater enterprise-level risk information, more precise risk terminology, quantifying risks to the greatest extent possible, reduced risk of non-compliance, and increased awareness and accountability among staff. Academics assert that holistic corporate-wide risk management results in a reduced total risk level (Kleffner 2003). ${ }^{7}$ The study asked the customs administrations to rank the relevance of customs risk management related benefits. Overall, the potential benefits of risk management support a customs administrations objective for achieving its overall organizational goals, i.e., to protect the safety of citizens, domestic industry, and sovereignty of state (USAID 2008). It is therefore a logical consequence that "achieving better overall organizational objectives" ranks above all other benefits. ${ }^{8}$

\footnotetext{
${ }^{6}$ The survey also revealed that risk management related information supports managers to make more informed decisions on risk-taking and risk retention.

7 It is also claimed that risk management programs establish a virtuous culture of vigilant risk monitoring in an organization. Kucuk (2006) concluded that successful risk management programs help business operations run more smoothly and effectively in a turbulent business environment.

8 The results also indicate strong assurance among customs that risk management is the key methodology to simultaneously
} 
The benefits relating to reputation are ranked between medium and high in relevance. Trusted relationships with the private sector have become a critical component for those customs administrations that have to manage ever increasing trade flows with the same (or even declining) workforce. A good reputation also plays a vital role in partnering with other customs administrations for sharing information (e.g., sharing seizure information, customs offences, and data related to new smuggling trends) or mutually recognizing AEO programs. In summary, it can be argued that organizations that manage risks effectively are more likely to achieve their objectives and do so at lower overall cost. ${ }^{9}$

\section{Concept of Risk Management Adoption in Customs Administration}

Recently, Customs Authority is working to ensure that risk management has become a mechanism to make the right decision on the high level, thereby reducing the administrative barriers for law-abiding businesses. The desire in the application of risk management systems meet the continuous cycle recommended by the WCO, several Asian countries met with the difficulties associated with synchronous operation of all elements of the risk management system.

Tamrazyan (2015) argues that in contrast to countries with a wealth of experience in these matters, one of the downsides for several jurisdictions is the weak development of the methodological framework. There are a number of methodologies aimed at identifying the risks according to the risk objects, but there are obstacles on the road to ensure synchronicity of existing techniques, which creates a certain imbalance in the application of customs control. It should be noted that in the framework of regulations of the Customs Union provides: the reduction of the share control of the declaration of goods at the expense of transfer of emphasis on control after the release and concentration of control measures at the sites selected on the basis of the risk management system; the refusal of the submission of documents and their electronic copies, without the recommendations of risk management system. ${ }^{10}$

Following the standard 4 of SAFE Framework and based on international best practices, in 2010 customs introduced the use of risk assessment in an automated form. Information system "Selective Control and Risk Management" (SCRM) is intended for the risk assessment and the issuance of decisions on the application of risk mitigation measures required under customs control. According to data published on official website of the State Revenue Committee (2016), since the introduction of the automated system customs clearance time reduced from 33 hours 36 minutes in 2010 to 17 hours and 20 minutes to the end of 2013. As for year 2015, the average time of customs clearance - export (56 min),

improve customs control and security on the one hand and trade facilitation on the other. In addition, the respondents expressed a consensus that by using risk management, customs can improve overall management processes, which eventually leads to improved risk-based resource allocation.

${ }^{9}$ In addition, a partnership-oriented relationship with the private sector and a good reputation for predictable and fast service delivery can have a significant impact on the competitiveness of the country and its attractiveness for foreign direct investments (Cross-border Research Association, 2011).

${ }^{10}$ However, the obvious contradiction associated with the risks that can be detected directly in the process of customs control of a object. Current legislation allows professionals to take measures to detect violations, even without the recommendations of the risk management system. Thus, while we cannot say about $100 \%$ control on the basis of the risk management system. 
import ( $2 \mathrm{~h} 52 \mathrm{~min}$ ). The current system allows customs to assess the risks at the stage of customs clearance, and make decisions at the stage of post-customs control, with minimal influence of the human factor.

Until now, the customs institution has operated a risk management system based on the principle of risk areas profiling. A risk profile is a collection of areas of risk, risk indicators, as well as guidance on the application of the necessary measures to prevent or minimize risks. To generate risk profiles, customs officials used a variety of sources including - base of customs bodies of data, operative information of law enforcement departments of customs, appeals, complaints and letters from citizens and legal entities, information from other government agencies, the media and the Internet. The decision-making process is depicted in Figure 2.

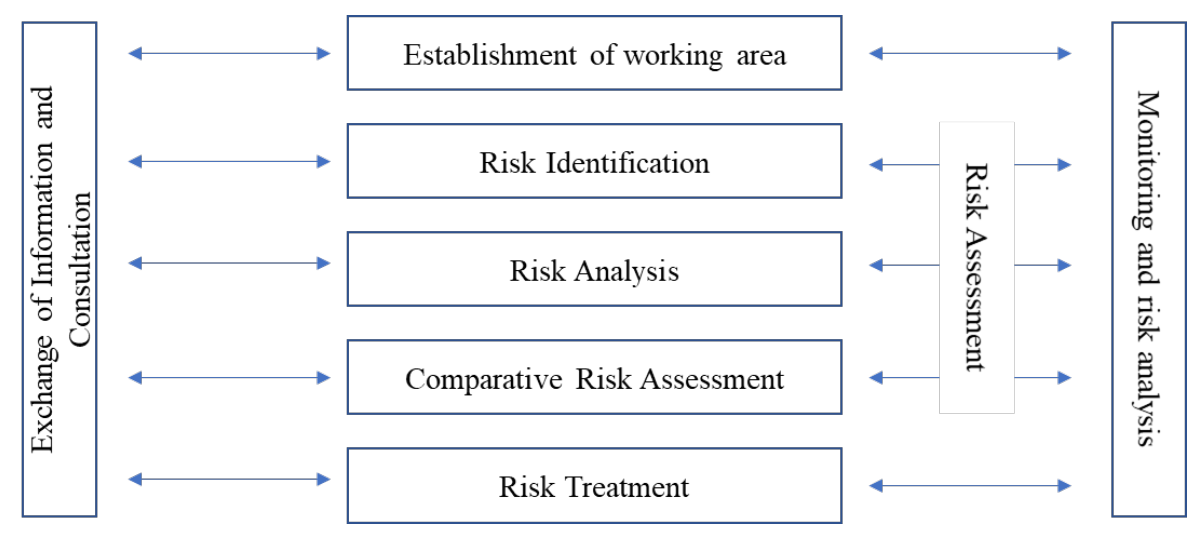

Source: Authors' Elaboration

Figure 2. Technology of decision-making process in the conditions of risk and uncertainty

Currently, in accordance with the compendium of risk management in customs authorities (WCO), the customs authorities carried out the segmentation of foreign economic activity in the individual category. Categorization helps reduce the number of inspections in respect of law-abiding businesses and focus on the participants of foreign economic activity are prone to violations of the law. Fixing the Institute of Authorized Economic Operator is another step in the provision of certain categories of persons enjoying the confidence of the customs authorities, the possibility of applying the simplified customs control. It important to be emphasized that this program, especially introduced for the convenience of traders, reducing time and financial costs of moving goods across the customs border, creating economic benefits associated with the simplification of the conditions for the realization of foreign trade activities, the emergence of new competitive advantages for the subjects of the national market, has a direct impact on the acceleration of the development of trade and industrial potential, strengthen the regional economy.

To discuss about the successful implementation of the system of risk management, we looked through the work done by the customs institution and risk management structure in countries studied above. First, as in most countries, the structure of customs risk assessment consists of gathering information, highlighting areas of potential high risk, risk assessment, risk minimization measures and monitoring and risk analysis. This approach shows the sequence 
in decisions-making process that clearly follows the recommendations of the WCO and practices of the countries studied. Second, a risk assessment system is also automated. Certainly, at the present stage the developing of risk management is very difficult without an established automated system, and there is not a single country with a successful organized system of risk management, without automated information platform. Third, great attention is paid to categorization of traders in recent years, on order to simplify law-abiding businesses and to reduce the number of customs inspections. Studying the structure of risk management in the customs of different countries, we have noticed that they are all in various forms reduce the administrative barriers during the customs clearance for the companies, who always complying with the customs laws.

However, despite the progress, can be seen several shortcomings of the current system. Unlike developed countries, practices, customs of developing countries have no integrated approach to decision-making. At the beginning of the implementation of the risk management subject to risk assessment was only the goods, recently the subject of risk assessment is the company itself, while, for instance, the US Customs Service estimates product, company and logistics at the same time, with the imposition of the total score on the basis of above assessment. In addition, the reduction in the number of identified criminal and administrative offenses may indicate that the system of risk management requires not merely the simplification of procedures for law-abiding businesses, but more integrated approach in the determination of risk areas.

\section{Customs Risk Management in Developed Jurisdiction}

Several developed jurisdictions including Australia and USA utilized a modern technology in the field of customs, the main of which can be called a risk management system in the process of customs control. The subject of the activities was the coordination of customs activities within each area, analysis and monitoring of the dynamics of trade turnover, as well as participation in the development of the customs authorities. An important step towards the improvement of risk management was the adoption of the framework of the principles of business planning and ongoing activities at customs with a view to harmonizing the issues of risk management and business planning across the enterprise and the industry.

This step can be characterized by the fact of its commercial needs as well as provides access to the necessary information relating to persons, goods and industries through the main connection with the importers, exporters, customs brokers, carriers and other interested parties. Assisting business is reflected in the scoring system of risk assessment, through which for traders who meet customs laws provided a simplified procedure of customs clearance. Given the characteristics of the goods and the country of origin, each declaration is assessed by a scoring system. The lowest score - means passing through a simplified customs control (green channel), the highest score - gives right to the customs for additional forms of customs control (red channel).

In summary, the following main components can be distinguished, due to which the above-mentioned countries have succeeded in building a risk management: (1) All of these countries in their work based primarily on close cooperation with business, studying the 
dossier of the companies, as a result - the construction of risk management on the basis of trust in the companies, who meet customs laws; (2) The risk management process is usually composed of similar components: risk analysis, risk assessment, implementation of risk minimization measures, monitoring and review of ineffective measures.

\section{Proposed Framework and Risk Management}

On the basis of studied examples, we have identified the following tasks in the revision of approaches to risk management: review and optimization of existing risk assessment approaches to customs control; the shift from an operational risk management to strategic risk management; the creation of a tactical level risk management; the establishment of a mechanism for effective and coherent application of strategic, tactical and operational risk management; shifting the focus to the subject-oriented risk assessment; expansion of data source analysis in the risk assessment; development and application of evaluation of the effectiveness of taken measures.

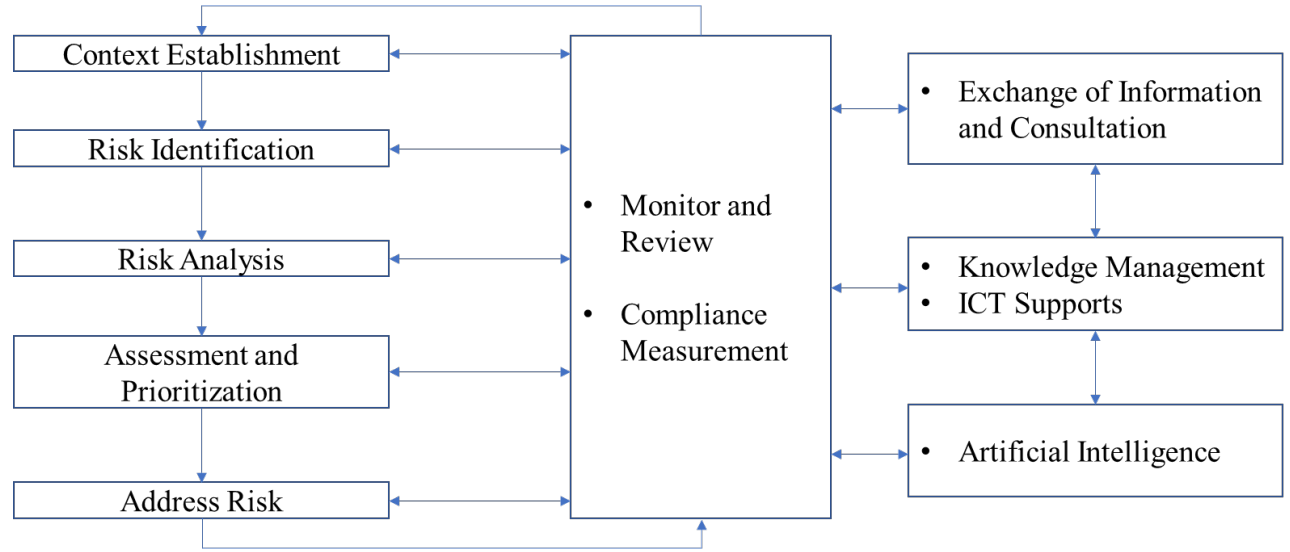

Source: Authors' Elaboration

Figure 3. Proposed Risk Management

Through the study of available information, the customs authorities need to identify areas of risk and spend the least significant intervention only in the areas of risk, where such intervention is necessary. Strategic risk management should be implemented by means of grading the risk assessment, i.e., based on the summary indicator, formed from several individual risk indicators. As a general indicator, and each individual measure of risk should consider the probability of the risk and the level of adverse effects. We should consider that each region conducts customs control with a different volume, structure of trade flows, risks, and other factors.

From the perspective of AI risk management, as suggested by Žigiene, Rybakovas and Alzbutas (2019) cognitive analysis or artificial intelligence helps to integrate complex large-scale data to indicate and integrate known and initially unknown risk factors for large business data processing by identifying risk factors for commercial processes. However, the elaboration should be driven to the practical application of AI risk management and its accuracy. With a growing number of AI options for the application, there is a need for an 


\section{Macrothink Institute ${ }^{\mathrm{TM}}$}

improved workforce when it comes to practical applications. Firms cannot simply 'apply' a machine learning risk management solution, but it is rather a continuous process requiring a constant evaluation of whether their machine learning solution is currently considered best practice. When it comes to AI, where there is some or full automation of processes, from data gathering to decision-making, the need for human oversight will become even more pressing.

Revision of the existing risk management system is necessary to empower the regions of the mandate and the corresponding set of tools to identify areas of risk and take measures to minimize them. The risk assessment results, the degree of riskiness, by assigning an object to a low, medium or high-risk area (green, yellow or red channels, respectively) must be defined for each individual object. Implementation of all the above activities should be carried out by expanding the functionality of the information system through the risk assessment in customs control.

The implementation of the tasks will: accelerate the procedures of customs clearance, minimize the human factor in the choice of objects of high-risk level, efficient use of the limited resources of government revenue agencies, reduce the burden on the regional government revenue agencies, increase the efficiency of the risk management system for customs control, simplify customs procedures administration for companies.

It is encouraging to analyze the brain area of risk assessment of an integrated customs control chain. Customs control and risk assessment for security purposes is an ongoing and shared process commencing at the time when goods are being prepared for export by the exporter and, through ongoing verification of consignment integrity, avoiding unnecessary duplication of controls. To enable such mutual recognition of controls, Customs should agree on consistent control and risk management standards, the sharing of intelligence and risk profiles as well as the exchange of Customs data, considering the work which has been carried out within the context of the WCO Global Information and Intelligence Strategy (GIIS). ${ }^{11}$

11 Such agreements should foresee the possibility of joint monitoring or quality control procedures to oversee the adherence to the standards. 


\begin{tabular}{|c|c|c|c|c|}
\hline Parameter & \multicolumn{4}{|c|}{ Risk Level } \\
\hline Client categories & $\begin{array}{l}\text { Voluntary } \\
\text { compliance - } \\
\text { People who want } \\
\text { to comply }\end{array}$ & $\begin{array}{l}\text { Assisted } \\
\text { compliance - } \\
\text { People who try to } \\
\text { comply, but do } \\
\text { not always } \\
\text { succeed }\end{array}$ & $\begin{array}{l}\text { Directed } \\
\text { Compliance- } \\
\text { People who will } \\
\text { avoid complying } \\
\text { if they can }\end{array}$ & $\begin{array}{l}\text { Enforced } \\
\text { compliance - } \\
\text { People who } \\
\text { deliberately do not } \\
\text { comply }\end{array}$ \\
\hline Client Behaviors & $\begin{array}{l}\text { - Voluntary } \\
\text { compliance } \\
\text { - Informed clients }\end{array}$ & $\begin{array}{l}\text { - Attempting to } \\
\text { comply } \\
\text { - Uninformed } \\
\text { clients }\end{array}$ & $\begin{array}{l}\text { - Resistance to } \\
\text { compliance } \\
\text { - Will avoid if } \\
\text { possible }\end{array}$ & $\begin{array}{l}\text { - Criminal intent } \\
\text { - Illegal activity }\end{array}$ \\
\hline Increasi & intervention by Cus & $\mathrm{ms}$ & & \\
\hline
\end{tabular}

Source: Modified from ISO Standard 31000

Figure 4. Level of Risk and Level of Compliance

The Compendium is comprised of two separate but interlinked volumes. Volume 1 deals with organizational aspects of risk management. It describes the different building blocks of an organizational risk management framework. Embedding risk management as an organizational culture and building risk management capacity in gradual steps are also included in Volume 1. Volume 2 deals with operational risk management. It includes "enforcement sensitive" material for "Customs only" purposes, including numerous practical guides and templates for assessing risks in relation to the movement of goods, people, conveyances, economic operators and other parties to international trade. The topics covered in Volume 2 can be categorized into four broad clusters: risk assessment, profiling and targeting; risk indicators; analysis; and information and intelligence. The Compendium is a living document and will be continually updated to reflect the latest developments regarding risk management practices in today's constantly changing Customs operating environment. Figure 3 shows these four categories of risk level. Customs administration should take a different strategy and methodology depending on the above risk level. For example, if the customs administration can increase the level of compliance from their client, it will have more resources to focus on the small group of people who are deliberately not to comply with the full enforcement of laws.

Furthermore, we analyzed the following tasks in the revision of approaches to risk management including (1) review and optimization of existing risk assessment approaches to customs control; (2) the shift from an operational risk management to strategic risk management; (3) the creation of a tactical level risk management; (4) the establishment of a mechanism for effective and coherent application of strategic, tactical and operational risk management; (5) shifting the focus to the subject-oriented risk assessment; (6) expansion of data source analysis in the risk assessment; and (7) development and application of evaluation of the effectiveness of taken measures.

Through the study of available information, the customs authorities need to identify areas of 
risk and spend the least significant intervention only in the areas of risk, where such intervention is necessary. Strategic risk management should be implemented by means of grading the risk assessment, i.e., based on the summary indicator, formed from several individual risk indicators. As a general indicator, and each individual measure of risk should consider the probability of the risk and the level of adverse effects. We should take into account that each region conducts customs control with a different volume, structure of trade flows, risks, and other factors.

However, it is also necessary to empower the regions of the mandate and the corresponding set of tools to identify areas of risk and take measures to minimize them. The risk assessment results, the degree of riskiness, by assigning an object to a low, medium or high-risk area (green, yellow or red channels, respectively) must be defined for each individual object. Implementation of all the above activities should be carried out by expanding the functionality of the information system through the risk assessment in customs control. ${ }^{12}$

\section{Conclusion}

Modern risk management is a relatively new area in the practice of the customs administration. This study has shown the importance of risk management in the process of trade facilitation and customs control. In our analysis we demonstrate that the following tasks in the revision of approaches to risk management including review and optimization of existing risk assessment approaches to customs control, shifting the operational risk management to strategic risk management; creating a tactical level risk management, establishing an effective and coherent application of strategic, focusing on the subject-oriented risk assessment, and developing application of evaluation of the effectiveness of taken measures. Technological approach such as artificial intelligence induced that cognitive analysis or artificial intelligence helps to integrate complex large-scale data to indicate and integrate known and initially unknown risk factors for customs management.

Further, we have highlighted the main features and shortcomings of customs risk management, and our striking result is a set of proposed frameworks to accelerate the procedures of customs clearance, minimize the human factor in the choice of objects of high-risk level, efficient use of the limited resources of government revenue agencies, reduce the burden on the regional government revenue agencies, increase the efficiency of the risk management system for customs control, simplify customs procedures administration for companies.

\section{References}

Aniszewski, S. (2011). Risk Assessment/Targeting centers: Study Report. WCO Research Paper No. 15. Retrieved January 16, 2016, from http://www.wcoomd.org/en/topics/research/activities-and-

\footnotetext{
12 The implementation of the tasks will: accelerate the procedures of customs clearance, minimize the human factor in the choice of objects of high-risk level, efficient use of the limited resources of government revenue agencies, reduce the burden on the regional government revenue agencies, increase the efficiency of the risk management system for customs control, simplify customs procedures administration for companies.
} 
programmes/ /media/F900606D77CE4B7790F53167F8364AB7.ashx

Ayral, S. (2016). TBT and trade facilitation agreements: Leveraging linkages to reduce trade $\begin{array}{lllll}\text { costs. } & \text { Retrieved } & \text { July } & 2016 & \text { from }\end{array}$ https://www.wto.org/english/res_e/reser_e/ersd201602_e.htm

Beverelli, C., Neumueller, S., \& Teh, R. (2014). A New Look at the Extensive Trade Margin Effects of Trade Facilitation. https://doi.org/10.2139/ssrn.2511573

Grainer, A. (2012) Customs and trade facilitation: from concepts to implementation. Customs Journal, 2, 1-23

Hintsa, E. (2011). Customs Risk Management (CRiM): a survey of 24 WCO member administrations. Cross-border Research Association, 26, 78-98

Laporte, G., \& Bertrand, J. (2011). Risk management systems: using data mining in developing countries' customs administrations. World Customs Journal, 5, 46-88. http://elibrary.worldbank.org/doi/abs/10.1596/0-8213- 5752-2

Milner, C., Morrissey O., \& Zgovu E. (2008). Trade facilitation in developing countries (Credit Research Paper, No. 08/05), Retrieved February 20, 2016 from https://www.nottingham.ac.uk/credit/documents/papers/08-05.pdf

Moïsé, E. (2013). The costs and challenges of implementing trade facilitation measures. $\begin{array}{lllll}\text { OECD Trade Policy } & \text { Papers, } & 157, & \end{array}$ http://documents.worldbank.org/curated/en/2004/01/5163770/customs-modernizationinitiatives-case-studies

Neufeld N. (2014). Trade facilitation provisions in regional trade agreements: traits and $\begin{array}{lllll}\text { trends. } & \text { Retrieved } & \text { March } & 246 & \text { from }\end{array}$ https://www.wto.org/english/res_e/reser_e/ersd201401_e.htm

Salaman, O. (2011). Risk management implementation in the different customs bodies in the world. Young Scientist, 11, 169-175. http://moluch.ru/archive/34/3892/

Tamrazyan, S. (2015). Customs risks: essence, management and evaluation. Retrieved January 16, 2016, from http://cyberleninka.ru/article/n/tamozhennye-riski-suschnost-upravlenie-i otsenka.pdf $+\& \mathrm{~cd}=1 \& \mathrm{hl}=\mathrm{en} \& \mathrm{ct}=\mathrm{clnk} \& \mathrm{gl}=\mathrm{jp}$

Tyshov, A. (2011). Risk management in customs authorities of United States of America. Proved, 26, 13-17.

Widdowson, D. (2003). Managing risk in the customs context. Retrieved March 23, 2016, from

http://customscentre.com/wp-content/uploads/2012/09/managing_risk_in_the-customs_conte xt.pdf

Wilson J. (2003). Trade facilitation and economic development. World Bank Working Paper 2988, http://www.worldbank.org/en/about/people/john-s-wilson 


\section{Macrothink}

Journal of Management Research

ISSN 1941-899X 2020, Vol. 12, No. 1

World Customs Organization. (1999). Revised Kyoto Convention. Retrieved May, 3, 2016 from http://www.wcoomd.org/en/topics/facilitation/instrument-andtools/conventions/pf_revised_kyoto_conv.aspx

World Customs Organization. (2007). SAFE Framework of Standards to Secure and Facilitate Global Trade. WCO: Brussels. Retrieved January 16, 2016, from http://www.wcoomd.org/en/topics/facilitation/instrument-and- tools/tools/safe_package.aspx

World Customs Organization. (2010). Background Paper on Risk Management. Retrieved May 17, 2016, from http://www.wcoomd.org/en/events/eventhistory/2010/ /media/2BA0488B399D4651BF8F0B6009C8040E.ashx

World Customs Organization. (2012). Compendium of Authorized Economic Operator Programmes. Retrieved January 16, 2016, from http://www.wcoomd.org/en/topics/research/activities-andprogrammes/ /media/930340C77B3740D6B3894F747AF6A7FF.ashx

Yasui, T. (2014). Trade Facilitation in Regional Trade Agreements. WCO Research Paper No. 30. Retrieved January 16, 2016, from http://www.wcoomd.org/en/topics/research/activities-and-programmes/ /media/F1506166AE 9F419FBCEE7B23F39739A4.ashx 